\title{
Influence of Multiple Donor Renal Arteries on the Outcome and Graft Survival in Deceased Donor Kidney Transplantation
}

\author{
Uwe Scheuermann ${ }^{1, * \mathbb{D}}$, Sebastian Rademacher ${ }^{1}$, Tristan Wagner ${ }^{1,2}$, Andri Lederer ${ }^{1}$, Hans-Michael Hau ${ }^{3}$, \\ Daniel Seehofer ${ }^{1}$ and Robert Sucher ${ }^{1}$ \\ 1 Department of Visceral, Transplantation, Vascular and Thoracic Surgery, University Hospital of Leipzig, \\ 04103 Leipzig, Germany; sebastian.rademacher@medizin.uni-leipzig.de (S.R.); \\ tristan.wagner@ukmuenster.de (T.W.); andri.lederer@medizin.uni-leipzig.de (A.L.); \\ daniel.seehofer@medizin.uni-leipzig.de (D.S.); robert.sucher@medizin.uni-leipzig.de (R.S.) \\ 2 Department of General, Visceral and Transplant Surgery, University Hospital Münster, \\ 48149 Münster, Germany \\ 3 Department of Visceral, Thoracic and Vascular Surgery, University Hospital Carl-Gustav-Carus, TU Dresden, \\ 01307 Dresden, Germany; hans-michael.hau@uniklinikum-dresden.de \\ * Correspondence: uwe.scheuermann@medizin.uni-leipzig.de
}

\section{check for} updates

Citation: Scheuermann, U.; Rademacher, S.; Wagner, T.; Lederer, A.; Hau, H.-M.; Seehofer, D.; Sucher, R. Influence of Multiple Donor Renal Arteries on the Outcome and Graft Survival in Deceased Donor Kidney Transplantation. J. Clin. Med. 2021, 10, 4395. https://doi.org/10.3390/ jcm10194395

Academic Editor: Lee Ann MacMillan-Crow

Received: 22 August 2021

Accepted: 22 September 2021

Published: 26 September 2021

Publisher's Note: MDPI stays neutral with regard to jurisdictional claims in published maps and institutional affiliations.

Copyright: (c) 2021 by the authors. Licensee MDPI, Basel, Switzerland. This article is an open access article distributed under the terms and conditions of the Creative Commons Attribution (CC BY) license (https:/ / creativecommons.org/licenses/by/ $4.0 /)$.

\begin{abstract}
Aim: Complex arterial reconstruction in kidney transplantation (KT) using kidneys from deceased donors (DD) warrants additional study since little is known about the effects on the midand long-term outcome and graft survival. Methods: A total of 451 patients receiving deceased donor KT in our department between 1993 and 2017 were included in our study. Patients were divided into three groups according to the number of arteries and anastomosis: (A) 1 renal artery, 1 arterial anastomosis $(N=369)$; $(\mathrm{B})>1$ renal artery, 1 arterial anastomosis $(N=47)$; and $(C)>1$ renal artery, $>1$ arterial anastomosis $(N=35)$. Furthermore, the influence of localization of the arterial anastomosis (common iliac artery (CIA), versus non-CIA) was analyzed. Clinicopathological characteristics, outcome, and graft and patient survival of all groups were compared retrospectively. Results: With growing vascular complexity, the time of warm ischemia increased significantly (groups A, $\mathrm{B}$, and $\mathrm{C}: 40 \pm 19 \mathrm{~min}, 45 \pm 19 \mathrm{~min}$, and $50 \pm 17 \mathrm{~min}$, respectively; $p=0.006$ ). Furthermore, the duration of operation was prolonged, although this did not reach significance (groups A, B, and C: $175 \pm 98 \mathrm{~min}, 180 \pm 35 \mathrm{~min}$, and $210 \pm 43 \mathrm{~min}$, respectively; $p=0.352$ ). There were no significant differences regarding surgical complications, post-transplant kidney function (delayed graft function, initial non-function, episodes of acute rejection), or long-term graft survival. Regarding the localization of the arterial anastomosis, non-CIA was an independent prognostic factor for deep vein thrombosis in multivariate analysis (CIA versus non-CIA: OR 11.551; 95\% CI, 1.218-109.554; $p=0.033$ ). Conclusion: Multiple-donor renal arteries should not be considered a contraindication to deceased KT, as morbidity rates and long-term outcomes seem to be comparable with grafts with single arteries and less complex anastomoses.
\end{abstract}

Keywords: kidney transplant; multiple arteries; anastomosis; reconstruction; outcome; delayed graft function; warm ischemia time; cold ischemia time; survival

\section{Introduction}

Kidney transplantation (KT) is the treatment of choice in patients with end-stage renal disease and it improves patient survival and recipients' quality of life compared to chronic dialysis treatment [1-3].

During kidney graft implantation, vascular anastomosis is one of the most challenging aspects for the transplant surgeon, and post-operative vascular complications such as bleeding or thrombosis can require surgical repair or even nephrectomy [4]. Complex arterial reconstructions are often necessary, as kidney grafts carry two or more arteries in about $30 \%$ of cases [5]. However, only a few publications have addressed the issue of 
multiple renal arteries and complex vascular reconstructions in KT using kidneys from deceased donors (DD). Indeed, most of them investigated KT after living donation (LD) or study groups including both LD and DD KT [6]. This could induce bias, as LD offers better pre-operative planning and pre-selection, as well as better graft outcome and survival rates than DD kidney grafts [1,7].

Therefore, this study aimed to investigate the impact of arterial reconstruction on outcome and graft survival in DD KT.

\section{Patients and Methods}

\subsection{Data Collection and Study Population}

Medical data from all adult patients ( $\geq 18$ years of age) who underwent initial deceased donor kidney transplantation at the University Hospital of Leipzig between October 1993 and December 2017 were retrospectively analyzed. Our data source comprised a prospectively collected electronic database. Patients undergoing living kidney transplantations, multi-organ transplants, re-transplants, machine preservation of donor kidneys, and transplants with graft anastomosis to the aorta or inferior vena cava were excluded from the study. Living KTs were excluded from the study, as deceased donor organs cannot be compared with living donor organs regarding graft outcome and survival rates. Follow-up data were collected up to March 2020.

Patients were divided into three groups according to the number of arteries and anastomosis: (A) 1 renal artery, 1 arterial anastomosis; (B) >1 renal artery, 1 arterial anastomosis; and $(\mathrm{C})>1$ renal artery, $>1$ arterial anastomosis.

Characteristics of the study population included donor and recipient age, gender, body mass index (BMI, weight in $\mathrm{kg}$ /height in $\mathrm{m}^{2}$ ), donor cause of death, duration of dialysis, and time on the waiting list. The criteria for expanded criteria donors (ECD) kidneys were donors over 60 years of age or donors between 50 and 59 years of age with at least two of the following three criteria: cerebrovascular death, arterial hypertension, or a donor serum creatinine level $>1.5 \mathrm{mg} / \mathrm{dL}$ [8]. Peri- and post-transplant data included information on cold (CIT) and warm ischemia time (WIT) of the grafts, duration of operation, and immunosuppressive therapy. CIT is defined as the time that the organ spent in cold preservation solution after removal from the donor. WIT is the time from cross-clamping until cold perfusion, plus the time of implantation (organ out of ice until reperfusion).

\subsection{Outcome Measures}

Outcome data included initial non-function (INF), episodes of acute rejection within 12 months after KT, delayed graft function (DGF), intra- and post-operative complications, date of graft failure, and patient death. INF was defined as dialysis dependence or creatinine clearance $\leq 20 \mathrm{~mL} / \mathrm{min}$ at three months post-transplant. Acute rejection episodes were histologically proved. DGF was defined as the requirement of dialysis in the first week following transplantation [9]. Using serum creatinine levels, the estimated glomerular filtration rate (eGFR) was calculated by the Chronic Kidney Disease Epidemiology Collaboration (CKD-EPI) equation $\left(\mathrm{mL} / \mathrm{min} / 1.73 \mathrm{~m}^{2}\right.$ of standard body surface area (BSA)) [10]. To reduce errors induced by indexing the glomerular filtration rate for body surface area, GFR was adjusted to individual patient body surface area $\left(\mathrm{eGFR} \times\right.$ individual BSA $\left[\mathrm{m}^{2}\right] / 1.73 \mathrm{~m}^{2}$ standard BSA $\left.=\mathrm{mL} / \mathrm{min}\right)[11,12]$. Post-operative complications occurring during the first three months after transplantation were analyzed. Complications included delayed wound healing, wound infection, urine leak, bleeding, and development of hematoma and lymphoceles. New-onset diabetes after transplantation (NODAT) was defined as the need for insulin or oral hypoglycemic drugs. Graft failure was defined as the return to dialysis or re-transplantation (patients who died before graft failure were censored). Post-operative mortality included all deaths occurring within 30 days after surgery. 


\subsection{Organ Procurement and Transplantation}

The kidney grafts were procured according to the guidelines provided by Eurotransplant (ET) and transplanted into the iliacal fossa. Kidneys were flushed in situ with cold HTK (histidin-tryptophan-ketoglutarat) solution and explanted. For static cold storage, grafts were immersed in HTK solution at $4{ }^{\circ} \mathrm{C}$ and stored in three separate bags, whereas the first bag was filled with preservation solution $[13,14]$. In general, for two renal arteries, the smaller branch was anastomosed to the side of the larger main renal artery. With two arteries of equal size, both were joined to form an ostium or anastomosed separately. In the case of three renal arteries, depending on the vessel diameter, one or two smaller vessel branches were anastomosed to the side of a main renal artery or reimplanted separately on the iliac vessels when the distance between the vessels was too high. Smaller vessels with high risk of thrombosis were frequently ligated. The preferred approach was reimplantation on a common Carrel patch (small portion of surrounding aorta) to avoid an individual reconstruction and impairment of the diameter of either the donor's or the recipient's vessel. In the case of multiple arteries, patches were combined by ex vivo reconstruction on the bench when the distance between the two vessels allowed the patches to be combined without tension. The ureter was implanted into the bladder according to the Lich-Gregoir technique using a double J intraureteral splint $[15,16]$.

\subsection{Immunosuppression}

Immunosuppressive therapy comprised an induction therapy with the interleukin-2 receptor antagonist basiliximab or antithymocyte globulin, followed by triple maintenance immunosuppression comprising calcineurin inhibitors (tacrolimus or cyclosporine), and/or mTOR inhibitors (everolimus or sirolimus), antimetabolites (mycophenolate mofetil), and tapered steroids (prednisolone).

\subsection{Statistical Analysis}

For comparison between the groups, the appropriate statistical significance test, including Student's $t$-test, the chi-squared test, analysis of variance (ANOVA), the Kruskal-Wallis test, and the Wilcoxon-Mann-Whitney test was used. Univariate and multivariate logistic regression analyses were used to evaluate the association between independent variables and binary outcomes of allograft function, and multivariate Cox proportional hazard analysis was applied to assess independent predictors of kidney graft failure. For multivariate analyses, we used a forward stepwise regression model including only clinically relevant variables and those presenting $p \leq 0.05$ in univariate analysis. Survival rates were calculated using the Kaplan-Meier analysis, and the log-rank test was applied to test statistical significance. Graft survival was calculated as the time from initial transplant to graft failure (re-start of dialysis), censoring for death with a functioning graft. Patient survival was defined as the time from transplant to patient death, censoring for patients still alive at the time of analysis. If a recipient was alive or lost to follow-up at the time of last contact, then survival time was censored at the time of last contact. SPSS software version 21.0 (SPSS Inc., Chicago, IL, USA) was used for statistical analysis. A $p$-value $<0.05$ was considered statistically significant.

\subsection{Literature Review}

A review of the literature on publications reporting results after renal transplantation with multiple renal arteries was performed using the Medline (Pubmed) database. The search algorithm included the following medical subject heading terms: kidney or renal transplant, multiple arteries, anastomosis, artery, and outcome. Articles written in languages other than English, articles without an abstract and/or full text, and those specific to the pediatric population were excluded. A manual search of the reference lists supplemented the electronic results. It yielded 53 potentially relevant original articles, of which 13 met the complete selection criteria (Supplementary Table S1) [17-29]. Publications were collected up to March 2021. 


\section{Results}

\subsection{Baseline Characteristics}

A total of 451 patients receiving primary deceased donor kidney transplantation (KT) were included in the study. The mean follow-up period was $7.6 \pm 5.7$ years. Among the overall study population, $81.8 \%$ of the kidney grafts had one $(N=369), 16.4 \%$ two $(N=74)$, and $7.8 \%$ had three $(N=35)$ renal arteries. In $92.2 \%(N=416)$ of the cases, a single arterial anastomosis was performed, in $6.7 \%(N=30)$ two were performed, and in $1.1 \%(N=5)$ three arterial anastomoses were performed. Donor, recipient, and transplant characteristics according to the different complexity of arterial anastomosis (groups A-C) are summarized in Table 1. The three groups were similar for most of their transplant characteristics. Warm ischemia time significantly increased with the complexity of arterial reconstruction (groups $\mathrm{A}, \mathrm{B}$, and C: $40 \pm 19 \mathrm{~min}, 45 \pm 19 \mathrm{~min}$, and $50 \pm 17 \mathrm{~min}$, respectively; $p=0.006$ ). Moreover, a longer operation time was associated with more complex arterial anastomoses, although this was not statistically significant (groups A, B, and C: $175 \pm 98 \mathrm{~min}, 180 \pm 35 \mathrm{~min}$, and $210 \pm 43$ min, respectively; $p=0.352)$.

Table 1. Donor, recipient, and transplant characteristics.

\begin{tabular}{|c|c|c|c|c|}
\hline \multirow{2}{*}{ Variables } & \multicolumn{3}{|c|}{ Group } & \multirow{2}{*}{$p$-Value } \\
\hline & A $(N=369)$ & B $(N=47)$ & $\mathrm{C}(N=35)$ & \\
\hline \multicolumn{5}{|l|}{ Donor } \\
\hline Age, years & $53 \pm 17.6$ & $49 \pm 18.4$ & $57 \pm 14.1$ & 0.429 \\
\hline Gender, male/female (\%) & $201(54.5) / 159(43.1)$ & $30(63.8) / 17(36.2)$ & $18(51.4) / 17(48.6)$ & 0.514 \\
\hline $\mathrm{BMI}, \mathrm{kg} / \mathrm{m}^{2}$ & $24.8 \pm 3.9$ & $24.5 \pm 3.2$ & $\begin{array}{l}18(1.4) / 17(48.6) \\
24.8 \pm 4.7\end{array}$ & $\begin{array}{l}0.514 \\
0.672\end{array}$ \\
\hline \multicolumn{5}{|l|}{ Cause of death $(\%)$} \\
\hline CAV & $200(54.2)$ & $22(46.8)$ & $16(45.7)$ & 0.152 \\
\hline Non-CAV, anoxia/ischemia/polytrauma/others/unknown & $35(9.5) / 34(9.2) / 50(13.6) / 15(4.1) / 1(0.3)$ & $3(6.4) / 7(14.9) / 6(12.8) / 2(4.3) / 1(2.1)$ & $1(2.9) / 7(20.0) / 3(8.6) / 4(11.4) / 0$ & \\
\hline \multicolumn{5}{|l|}{ Comorbidity (\%) } \\
\hline Diabetes mellitus & $32(8.7)$ & $5(10.6)$ & $2(5.7)$ & 0.734 \\
\hline Hypertension & $136(36.9)$ & $21(44.7)$ & $12(34.3)$ & 0.534 \\
\hline ECD $(\%)$ & $157(42.5)$ & $19(40.4)$ & $17(48.6)$ & 0.743 \\
\hline \multicolumn{5}{|l|}{ Recipient } \\
\hline Age, years & $55.9 \pm 13.2$ & $53.2 \pm 14.4$ & $53.6 \pm 11.7$ & 0.652 \\
\hline Gender, male/female (\%) & $213(57.7) / 138(37.4)$ & $31(66.0) / 16(34.0)$ & $17(48.6) / 18(51.4)$ & 0.219 \\
\hline $\mathrm{BMI}, \mathrm{kg} / \mathrm{m}^{2}$ & $25.0 \pm 4.2$ & $24.8 \pm 3.9$ & $25.2 \pm 3.1$ & 0.576 \\
\hline \multicolumn{5}{|l|}{ Cause of ESRD $(\%)$} \\
\hline \multirow{2}{*}{$\begin{array}{l}\text { Glomerulonephritis } \\
\text { Non-glomerulonephritis, diabetes mellitus/cystic kidney } \\
\text { disease/interstitial nephritis/others }\end{array}$} & $126(34.1)$ & $21(44.7)$ & $11(31.4)$ & 0.013 \\
\hline & $24(6.5) / 58(15.7) / 43(11.7) / 118(32.0)$ & $3(6.4) / 14(29.8) / 1(2.1) / 8(17.0)$ & $0 / 12(34.3) / 0 / 12(34.3)$ & \\
\hline \multicolumn{5}{|l|}{ Comorbidity (\%) } \\
\hline Diabetes mellitus & $65(17.6)$ & $4(8.5)$ & $4(11.4)$ & 0.201 \\
\hline Hypertension & $342(92.7)$ & $41(87.2)$ & $32(91.4)$ & 0.427 \\
\hline Coronary disease & $53(14.4)$ & $11(23.4)$ & $8(22.9)$ & 0.143 \\
\hline PVD & $28(7.6)$ & $3(6.4)$ & $3(8.6)$ & 0.930 \\
\hline \multirow{2}{*}{\multicolumn{5}{|c|}{$\begin{array}{l}\text { Transplant } \\
\text { Transplantera }(\%)\end{array}$}} \\
\hline \multicolumn{3}{|l|}{ Transplant era (\%) } & & \\
\hline $1993-2001 / 2002-2009 / 2010-2017$ & $126(34.1) / 120(32.5) / 123(33.3)$ & $17(36.2) / 19(40.4) / 11(23.4)$ & $7(20.0) / 15(42.9) / 13(37.1)$ & 0.271 \\
\hline CIT, hours & $12.5 \pm 6.2$ & $11.4 \pm 4.5$ & $11.3 \pm 5.5$ & 0.421 \\
\hline Number renal arteries, $1 / 2 / 3(\%)$ & $369(100) / 0 / 0$ & $0 / 44(93.6) / 3(6.4)$ & $0 / 30(85.7) / 5(14.3)$ & $<0.001$ \\
\hline \multicolumn{5}{|l|}{ Arterial anastomosis $(\%)$} \\
\hline Number, $1 / 2 / 3$ & $369(100) / 0 / 0$ & $47(100) / 0 / 0$ & $0 / 30(85.7) / 5(14.3)$ & $<0.001$ \\
\hline Location, IIA/EIA/CIA & $8(2.2) / 67(18.2) / 283(76.7)$ & $2(4.3) / 8(17.0) / 36(76.6)$ & $0 / 14(40.0) / 21(60.0)$ & 0.033 \\
\hline Patch & $215(58.3)$ & $39(83.0)$ & $22(62.9)$ & 0.005 \\
\hline WIT, minutes & $40 \pm 19$ & $45 \pm 19$ & $50 \pm 17$ & 0.006 \\
\hline \multirow{2}{*}{\multicolumn{5}{|c|}{$\begin{array}{l}\text { Ureterocystoneostomy }(\%) \\
\text { Intra-operative complications (\%) }\end{array}$}} \\
\hline & & & & \\
\hline Bleeding & $16(4.3)$ & $1(2.1)$ & $3(8.6)$ & 0.366 \\
\hline Thrombosis renal artery & $10(2.7)$ & $1(2.1)$ & $1(2.9)$ & 0.970 \\
\hline Thrombosis renal vein & $6(1.6)$ & 0 & 0 & 0.509 \\
\hline Duration of surgery, minutes & $175 \pm 98$ & $180 \pm 35$ & $210 \pm 43$ & 0.352 \\
\hline
\end{tabular}

Data are shown as median \pm SD. BMI, body mass index; CIA, common iliac artery; CIT, cold ischemia time; CVA, cerebrovascular event; ECD, expanded criteria donors; ESRD, end-stage renal disease; EIA, external iliac artery; IIA, internal iliac artery; PVD, peripheral vascular disease; WIT, warm ischemia time.

\subsection{Outcome}

The analysis of post-operative outcome parameters is shown in Table 2. There were neither significant differences regarding post-transplant kidney function parameters nor post-operative complications between the three groups.

In the overall study population, 27 kidneys lost their function in the first three months (initial non-function, INF) (groups A, B, and C: 20, 5, and 2, respectively, $p=0.352$ ), whereas permanent lack of graft function from the time of transplantation (primary non-function) was observed in six cases (groups A, B, and C: 4, 1, and 1, respectively; $p=0.603$ ). 
The most frequent post-operative complications were secondary wound healing $(N=97,21.5 \%)$, secondary bleeding and hematoma $(N=89,19.7 \%)$, and lymphoceles $(N=58,12.9 \%)$. The total number of vascular complications was relatively low (arterial stenosis and/or thrombosis: $N=10,2.2 \%$ ). No differences in hospital stay (groups A, B, and C: $25 \pm 16.2$ days, $24 \pm 16.5$ days, and $22 \pm 17.4$ days, respectively; $p=0.817$ ) were noted.

Table 2. Post-operative outcome parameters and immunosuppression after deceased donor kidney transplantation.

\begin{tabular}{|c|c|c|c|c|}
\hline \multirow{2}{*}{ Variables } & \multicolumn{3}{|c|}{ Group } & \multirow{2}{*}{$p$-Value } \\
\hline & A $(N=369)$ & B $(N=47)$ & $\mathrm{C}(N=35)$ & \\
\hline \multicolumn{5}{|l|}{ Kidney function } \\
\hline INF $(\%)$ & $20(5.4)$ & $5(10.6)$ & $2(5.7)$ & 0.351 \\
\hline DGF $(\%)$ & $109(29.5)$ & $12(25.5)$ & $12(34.3)$ & 0.726 \\
\hline Acute rejection (\%) & $101(27.4)$ & $11(23.4)$ & $9(25.7)$ & 0.815 \\
\hline \multicolumn{5}{|l|}{ Laboratory tests } \\
\hline GFR (mL/min), POD7 & $30.5 \pm 37.3$ & $40.0 \pm 36.6$ & $22.0 \pm 33.0$ & 0.919 \\
\hline GFR (mL/min), POM1 & $74.4 \pm 36.5$ & $86.2 \pm 39.6$ & $76.9 \pm 41.9$ & 0.237 \\
\hline \multicolumn{5}{|l|}{ Surgical outcome } \\
\hline RBC substitution (\%) & $106(28.7)$ & $18(38.3)$ & $10(28.6)$ & 0.396 \\
\hline Time in ICU, days & $5 \pm 5.7$ & $5 \pm 3.3$ & $5 \pm 2.5$ & 0.471 \\
\hline Hospitalization, days & $25 \pm 16.2$ & $24 \pm 16.5$ & $22 \pm 17.4$ & 0.817 \\
\hline \multicolumn{5}{|l|}{ Post-operative complications (\%) } \\
\hline Deep-vein thrombosis & $5(1.4)$ & 0 & $1(2.9)$ & 0.533 \\
\hline \multicolumn{5}{|l|}{ Stenosis } \\
\hline Renal artery & $2(0.5)$ & 0 & 0 & 0.800 \\
\hline Renal vein & $1(0.3)$ & 0 & 0 & 0.895 \\
\hline \multicolumn{5}{|l|}{ Thrombosis } \\
\hline Renal artery & $3(0.8)$ & $2(4.3)$ & 0 & 0.085 \\
\hline Renal vein & $7(1.9)$ & $1(2.1)$ & $1(2.9)$ & 0.925 \\
\hline Bleeding/hematoma & $68(18.4)$ & $12(25.5)$ & $9(25.7)$ & 0.335 \\
\hline Secondary wound healing & $80(21.7)$ & $12(25.5)$ & $5(14.3)$ & 0.463 \\
\hline Burst abdomen & $7(1.9)$ & $1(2.1)$ & $1(2.9)$ & 0.925 \\
\hline Urine leakage & $13(3.5)$ & $1(2.1)$ & 0 & 0.473 \\
\hline Lymphocele & $47(12.7)$ & $4(8.5)$ & $7(20.0)$ & 0.303 \\
\hline \multicolumn{5}{|l|}{ Metabolic } \\
\hline NODAT $(\%)$ & $21(5.7)$ & 0 & $4(11.4)$ & 0.079 \\
\hline \multicolumn{5}{|l|}{ Immunosuppression } \\
\hline Induction therapy $(\%)$ & $129(35.0)$ & $15(31.9)$ & $15(42.9)$ & 0.676 \\
\hline \multicolumn{5}{|l|}{ Maintenance therapy (\%) } \\
\hline $\mathrm{CNI}, \mathrm{Tac} / \mathrm{CsA}$ & 209 (56.6)/148 (40.1) & 28 (59.6) /17 (36.2) & $25(71.4) / 9(25.7)$ & 0.184 \\
\hline mTOR inhibitor, Ever/Siro & $2(0.5) / 9(2.4)$ & $0 / 0$ & $0 / 1(2.9)$ & 0.833 \\
\hline CNI + mTOR inhibitor & $11(3.0)$ & 0 & $1(2.9)$ & 0.491 \\
\hline AM drug, MMF (\%) & $326(88.3)$ & $43(91.5)$ & $34(97.1)$ & 0.223 \\
\hline Steroids, prednisolone & $353(95.7)$ & $43(91.5)$ & $33(94.3)$ & 0.361 \\
\hline Post-operative mortality (\%) & $5(1.4)$ & $2(4.3)$ & $1(2.9)$ & 0.322 \\
\hline
\end{tabular}

Data are shown as median \pm SD. AM, antimetabolite; CNI, calcineurin inhibitor; CsA, ciclosporin A; DGF, delayed graft function; Ever, everolimus; GFR, glomerular filtration rate; ICU, intensive care unit; INF, initial non-function; MMF, mycophenolate mofetil; mTOR, mechanistic target of rapamycin; NODAT, new-onset diabetes mellitus after transplantation; POD, post-operative day; POM, post-operative month; RBC, red blood cells; Siro, sirolimus; Tac, tacrolimus.

Eight of the 451 patients $(1.8 \%)$ died in the immediate post-operative course within the first 30 days after surgery. Overall, post-operative mortality was comparable between the groups (groups A, B, and C: 5, 2, and 1, respectively; $p=0.322$ ). The causes of death included multiple organ failure $(N=2)$, septic shock $(N=1)$, intracerebral hemorrhage $(N=1)$, and fatal heart attack $(N=1)$ in group $\mathrm{A}$; decompensated heart failure $(N=1)$ and acute bleeding with cardiovascular arrest $(N=1)$ in group $\mathrm{B}$; and decompensated heart failure $(N=1)$ in group $C$.

Univariate regression analyses of post-operative outcomes associated with the complexity of arterial anastomosis (groups A-C) and anastomosis localization are displayed in Table 3. Patients in group B were more likely to have renal artery thrombosis (OR 5.422; 
95\% CI: 0.882-33.342; $p=0.068$, whereas no case of thrombosis was reported in group $\mathrm{C}$. There was no significant difference between the two groups regarding post-transplant kidney function parameters (INF, DGF, acute rejection).

Table 3. Univariate analysis of kidney transplant outcome according to the complexity of arterial reconstruction and localization of arterial anastomosis.

\begin{tabular}{|c|c|c|c|c|c|c|c|c|c|c|c|}
\hline \multirow{4}{*}{ Variables } & \multicolumn{7}{|c|}{ Group } & \multicolumn{4}{|c|}{ Location of Arterial Anastomosis } \\
\hline & \multirow[t]{3}{*}{$\mathbf{A}$} & \multicolumn{3}{|c|}{ B } & \multicolumn{3}{|c|}{$\mathrm{C}$} & \multirow[t]{3}{*}{ CIA } & \multicolumn{3}{|c|}{ Non-CIA } \\
\hline & & \multicolumn{3}{|c|}{ Univariate Analysis } & \multicolumn{3}{|c|}{ Univariate Analysis } & & \multicolumn{3}{|c|}{ Univariate Analysis } \\
\hline & & OR & $95 \% \mathrm{CI}$ & $p$ & OR & $95 \% \mathrm{CI}$ & $p$ & & OR & $95 \% \mathrm{CI}$ & $p$ \\
\hline \multicolumn{12}{|l|}{ Complications } \\
\hline RBC substitution & 1.00 & 1.540 & $0.820-2.891$ & 0.400 & 0.992 & $0.461-2.138$ & 0.985 & 1.00 & 0.960 & $0.585-1.577$ & 0.872 \\
\hline Thrombosis renal artery & 1.00 & 5.422 & $0.882-33.324$ & 0.068 & $\mathrm{~N} / \mathrm{A}$ & $\mathrm{N} / \mathrm{A}$ & $\mathrm{N} / \mathrm{A}$ & 1.00 & 4.730 & $1.041-21.500$ & 0.044 \\
\hline Thrombosis renal vein & 1.00 & 1.124 & $0.135-9.344$ & 0.914 & 1.521 & $0.182-12.730$ & 0.699 & 1.00 & 0.375 & $0.047-2.999$ & 0.355 \\
\hline Secondary bleeding & 1.00 & 1.518 & $0.749-3.076$ & 0.247 & 1.532 & $0.687-3.418$ & 0.297 & 1.00 & 0.950 & $0.539-1.674$ & 0.859 \\
\hline Deep-vein thrombosis & 1.00 & $\mathrm{~N} / \mathrm{A}$ & N/A & $\mathrm{N} / \mathrm{A}$ & 2.141 & $0.243-18.859$ & 0.493 & 1.00 & 7.116 & $1.284-39.444$ & 0.025 \\
\hline \multicolumn{12}{|l|}{ Kidney function } \\
\hline INF & 1.00 & 2.104 & $0.749-5.905$ & 0.158 & 1.045 & $0.234-4.670$ & 0.954 & 1.00 & 1.598 & $0.673-3.796$ & 0.288 \\
\hline DGF & 1.00 & 0.829 & $0.414-1.661$ & 0.597 & 1.225 & $0.589-2.551$ & 0.587 & 1.00 & 0.730 & $0.436-1.222$ & 0.231 \\
\hline Acute rejection & 1.00 & 0.806 & $0.394-1.648$ & 0.554 & 0.888 & $0.402-1.960$ & 0.768 & 1.00 & 0.613 & $0.351-1.068$ & 0.084 \\
\hline Graft failure & 1.00 & 0.751 & $0.363-1.553$ & 0.440 & 0.918 & $0.399-2.110$ & 0.840 & 1.00 & 0.856 & $0.483-1.516$ & 0.594 \\
\hline
\end{tabular}

95\% CI, 95\% confidence interval; CIA, common iliac artery; DGF, delayed graft function; EIA, external iliac artery; IIA, internal iliac artery; INF, initial non-function; N/A, not available; OR, odds ratio; RBC, red blood cells.

Furthermore, in the univariate regression model, outcome parameters significantly associated with the localization of arterial anastomoses (CIA versus non-CIA) were thrombosis of the renal artery (OR 4.730; 95\% CI 1.041-21.500; $p=0.044)$ and deep-vein thrombosis (OR 7.116; 95\% CI 1.284-39.444; $p=0.025$ ). Univariate risk analysis showed no correlation between cause of renal failure, warm ischemia time, the use of arterial patches, and post-operative outcome parameters (Supplementary Table S2).

In the multivariate regression analysis, complexity of arterial reconstruction (groups AC) failed to be an independent predictor of post-operative complications and graft function. However, multivariate analysis showed that the localization of arterial anastomoses is an independent prognostic factor for deep-vein thrombosis (OR 11.551; 95\% CI, 1.218-109.554; $p=0.033)$ (Table 4).

Table 4. Multivariate analysis of kidney transplant outcome parameters.

\begin{tabular}{|c|c|c|c|c|c|c|}
\hline \multirow{2}{*}{ Variables } & \multicolumn{3}{|c|}{ Thrombosis Renal Artery } & \multicolumn{3}{|c|}{ Deep-Vein Thrombosis } \\
\hline & OR & $95 \% \mathrm{CI}$ & $p$-Value & OR & $95 \%$ CI & $p$-Value \\
\hline Arterial patch & 0.339 & $0.015-7.816$ & 0.499 & 0.616 & $0.095-3.988$ & 0.611 \\
\hline $\begin{array}{l}\text { Location of arterial anastomosis } \\
\text { (CIA vs. Non-CIA) }\end{array}$ & 2.864 & $0.165-49.692$ & 0.470 & 11.551 & $1.218-109.554$ & 0.033 \\
\hline \multicolumn{7}{|l|}{ Group } \\
\hline $\mathrm{A}$ & ref & & & ref & & \\
\hline $\mathrm{B}$ & 13.595 & $0.577-320.067$ & 0.105 & $\mathrm{~N} / \mathrm{A}$ & $\mathrm{N} / \mathrm{A}$ & $\mathrm{N} / \mathrm{A}$ \\
\hline C & $\mathrm{N} / \mathrm{A}$ & $\mathrm{N} / \mathrm{A}$ & $\mathrm{N} / \mathrm{A}$ & 1.061 & 0.101-11.096 & 0.611 \\
\hline WIT & 0.735 & $0.040-13.446$ & 0.835 & 1.332 & $0.203-8.747$ & 0.765 \\
\hline
\end{tabular}

95\% CI, 95\% confidence interval; OR, odds ratio; WIT, warm ischemia time.

\subsection{Graft and Patient Survival}

The one-, three-, five-, and 10-year kidney graft survival rates were $96 \%, 89 \%, 85 \%$, and $72 \%$ in group $\mathrm{A}, 91 \%, 91 \%, 85 \%$, and $78 \%$ in group $\mathrm{B}$, and $88 \%, 85 \%, 81 \%$, and $81 \%$ in group C $(p=0.733)$, respectively. Mean kidney graft survival decreased with the increasing complexity of arterial anastomoses, although these trends were not statistically significant among the groups (groups A, B, and C: $191 \pm 7.1$ months, $182 \pm 14.6$ months, and $147 \pm 11.3$ months, respectively; $p=0.733$ ). Overall long-term patient survival at one, 
three, five, and 10 years was 95\%, 90\%, 87\%, and 74\% in group A, 96\%, 91\%, 91\%, and 83\% in group $\mathrm{B}$, and $94 \%, 91 \%, 88 \%$, and $80 \%$ in group C ( $p=0.633)$, respectively.

\section{Discussion}

Multiple renal arteries are the Achilles heel of KT and lead to complications, especially during graft implantation and the early post-transplant course. In our series, $18.2 \%$ of the kidney grafts had multiple renal arteries, and in about $7.7 \%$ of the cases more than one arterial anastomosis was created. These results are comparable with reports of autopsies and previous studies in KT [5,17-29].

\subsection{Vascular Complications}

Most of the previously published reports showed higher rates of vascular complications in kidney grafts with multiple renal arteries (MRA) compared to single anastomosis [17-29]. Consecutive inadequate perfusion can lead to transplant infarction, ureteral necrosis, and a higher rate of graft loss. Renal artery stenosis occurred among $0.1 \%$ to $18.8 \%$ of KT with MRA and became primarily symptomatic through hypertension and functional impairment of the graft six months to three years after KT [17,19,21,24]. In a study published by Benedetti et al. in 1998 investigating the outcome of approximately $1000 \mathrm{KT}$, MRA was an independent risk factor for arterial stenosis in multivariate analysis $(p=0.04)$. Interestingly, arterial stenosis only occurred in cases with MRA on common aortic patches, not on reconstructed MRA patches [17]. In our series, the most common vascular complications were arterial thromboses, although no significant differences or independent effects in the adjusted analysis were observed among groups A-C. However, the localization of renal artery anastomosis seems to have a significant impact on the thrombosis rate. Usually, end-to-side anastomosis between the renal artery and the common iliac artery (CIA) is performed. Less frequently, the renal artery is anastomosed with the external iliac artery, or an end-to-end reconstruction is created with the internal iliac artery. Moreover, as described in the literature, end-to-end anastomosis to the internal iliac could increase the risk of erectile dysfunction in men [30]. In our series, anastomoses to the external or internal iliac artery were associated with a higher risk of arterial thrombosis and deep-vein thrombosis. Therefore, anastomoses to the CIA should be preferred whenever possible.

\subsection{Delayed Graft Function}

In the reviewed studies investigating $\mathrm{KT}$ after deceased donation, two reports showed delayed graft function (DGF) data with a slight insignificant increase in DGF in the MA groups [22,26]. DGF is thought to be a result of immunologically and ischemic-induced graft injury $[7,9]$. However, although reconstruction of multiple arteries led to a significantly prolonged time of warm ischemia and increased time of surgery in our cohort, rates of delayed graft function (DGF) were comparable among groups A-C (complexity of arterial reconstruction). Other donor characteristics like the type of donation could trigger DGF. In general, the percentage of DGF after deceased donor KT is inherently higher compared to living donor KT. The prevalence of DGF ranged from $4 \%$ to $10 \%$ in patients after living $\mathrm{KT}$, and between $2 \%$ and $50 \%$ in kidneys from brain-dead donors [7,31]. Interestingly, a meta-analysis by Zorgdrager et al. showed significantly more DGF in MA grafts than in grafts with single renal arteries but failed to be significant when studies with deceased donor grafts were excluded [6]. However, the available data are incomplete, and studies do not allow a linkage to be made between donor type and DGF, which probably caused significant heterogeneity in the analysis.

\subsection{Graft Survival}

Long-term outcomes and especially graft survival rates seem to be comparable between kidney grafts with single and multiple arteries. However, most published studies investigated KT after living donation (LD) or mixed cohorts comprising both LD and DD KTs [6,17-29]. This critical difference could have induced bias, as LD kidney grafts cannot 
be compared to DD kidney grafts regarding graft outcome and survival rates [1,7,32]. Moreover, compared to DD, LD offers better pre-operative planning and pre-selection, whereby the total ischemia time is usually shorter in LD KT.

\subsection{Limiting Factors}

There are some limiting factors of this study. First, one limitation of our study is the relatively low number of patients with multiple arteries and complex arterial anastomoses and its monocentric, retrospective non-randomized design. Second, the long investigation period makes further controlled and prospective studies necessary.

\section{Conclusions}

In conclusion, based on our data, complex arterial reconstructions of multiple renal arteries are not a limiting factor in kidney transplants regarding early post-operative outcomes and long-term graft survival. However, the localization of the renal artery anastomosis was associated with deep-vein thrombosis, and anastomoses to the internal or external iliac recipient artery should be avoided whenever possible.

Supplementary Materials: The following are available online at https://www.mdpi.com/article/ 10.3390/jcm10194395/s1, Table S1: Previous publications (1995-2021) investigating influence of multiple renal arteries in study groups including deceased donor kidney transplantation, Table S2: Univariate analysis of kidney transplant outcome according to the cause of renal failure, warm ischemia time and the use of arterial patches for anastomoses.

Author Contributions: Conceptualization, U.S. and S.R.; data acquisition, U.S. and T.W.; formal analysis, U.S., H.-M.H. and S.R.; writing-review and editing, U.S., R.S., A.L. and D.S. All authors have read and agreed to the published version of the manuscript.

Funding: This work was supported by the Open Access Publication Fund of the University of Leipzig. The funders had no role in the study design, data collection and analysis, decision to publish, or preparation of the manuscript. There are no potential conflicts of interest arising from associations with commercial or corporate interests in connection with the work submitted.

Institutional Review Board Statement: The study was conducted according to the guidelines of the Declaration of Helsinki and approved by the local ethical commission board from the University of Leipzig (AZ EK: 111-16-14032016).

Informed Consent Statement: Written informed consent from any patient for data collection in a prospectively collected database is available. However, written informed consent to the study was waived by the local Ethics Committee (Ethics Committee of the first affiliated University Hospital of Leipzig University) in view of the retrospective design of the study, according to the national and local guidelines, such as the fact that all clinical/laboratory measurements and procedures were part of the routine care.

Data Availability Statement: Our database contains highly sensible data that may provide insight into clinical and personnel information about our patients and lead to identification of these patients. Therefore, according to organizational restrictions and regulations these data cannot be made publicly available. However, the datasets used and/or analyzed during the current study are available from the corresponding author on reasonable request.

Conflicts of Interest: The authors declare that they have no conflict of interest.

\section{References}

1. Rana, A.; Gruessner, A.; Agopian, V.G.; Khalpey, Z.; bin Riaz, I.; Kaplan, B.; Halazun, K.; Busuttil, R.W.; Gruessner, R.W.G. Survival Benefit of Solid-Organ Transplant in the United States. JAMA Surg. 2015, 150, 252-259. [CrossRef]

2. Sureshkumar, K.K.; Patel, B.M.; Markatos, A.; Nghiem, D.D.; Marcus, R.J. Quality of life after organ transplantation in type 1 diabetics with end-stage renal disease. Clin. Transplant. 2006, 20, 19-25. [CrossRef]

3. Tonelli, M.; Wiebe, N.; Knoll, G.; Bello, A.; Browne, S.; Jadhav, D.; Klarenbach, S.; Gill, J. Systematic Review: Kidney Transplantation Compared With Dialysis in Clinically Relevant Outcomes. Arab. Archaeol. Epigr. 2011, 11, 2093-2109. [CrossRef]

4. Humar, A.; Matas, A.J. Surgical Complications After Kidney Transplantation. Semin. Dial. 2005, 18, 505-510. [CrossRef] [PubMed] 
5. Sośnik, H.H.; Sośnik, K. Investigations on renal vascularisation pathology in the Polish population. 1. Incidence of multiple kidney arteries. Folia Morphol. 2017, 76, 226-231. [CrossRef] [PubMed]

6. Zorgdrager, M.; Krikke, C.; Hofker, S.H.; Leuvenink, H.; Pol, R.A. Multiple Renal Arteries in Kidney Transplantation: A Systematic Review and Meta-Analysis. Ann. Transplant. 2016, 21, 469-478. [CrossRef] [PubMed]

7. Perico, N.; Cattaneo, D.; Sayegh, M.H.; Remuzzi, G. Delayed graft function in kidney transplantation. Lancet 2004, 364, 1814-1827. [CrossRef]

8. Rao, P.S.; Ojo, A. The alphabet soup of kidney transplantation: SCD, DCD, ECD—Fundamentals for the practicing nephrologist. Clin. J. Am. Soc. Nephrol. 2009, 4, 1827-1831. [CrossRef]

9. Siedlecki, A.; Irish, W.; Brennan, D.C. Delayed Graft Function in the Kidney Transplant. Arab. Archaeol. Epigr. 2011, 11, 2279-2296. [CrossRef] [PubMed]

10. Levey, A.S.; Stevens, L.A.; Schmid, C.H.; Zhang, Y.; Castro, A.F., 3rd; Feldman, H.I.; Kusek, J.W.; Eggers, P.; Van Lente, F.; Greene, T.; et al. A new equation to estimate glomerular filtration rate. Ann. Intern. Med. 2009, 150, 604-612, Erratum in 2011, $155,408$. [CrossRef]

11. Du Bois, D.; Du Bois, E.F. A formula to estimate the approximate surface area if height and weight be known. Nutrition 1989, 5, 303-311, discussion 312-313. [PubMed]

12. Zieschang, S. Genau richtig dosieren“ bei Niereninsuffizienz-aber wie? Arzneiverordnung in der Praxis Band 47 Heft 1-2 März 2020. Available online: https:/ / www.akdae.de/Arzneimitteltherapie/AVP/Artikel/2020-1-2/018h/index.php (accessed on 20 July 2021).

13. Eurotransplant. Chapter 9: The Donor. 2020. Available online: https://www.eurotransplant.org/wp-content/uploads/2020/01/ H9-The-Donor-Februar-2020.pdf (accessed on 11 July 2021).

14. Ladurner, R.; Steurer, W. Technik der Multiorganentnahme. Viszeralchirurgie 2004, 39, 439-442. [CrossRef]

15. Sollinger, H.W.; Odorico, J.S.; Becker, Y.T.; D'Alessandro, A.M.; Pirsch, J.D. One Thousand Simultaneous Pancreas-Kidney Transplants at a Single Center With 22-Year Follow-Up. Ann. Surg. 2009, 250, 618-630. [CrossRef] [PubMed]

16. Sollinger, H.W.; Odorico, J.S.; Knechtle, S.J.; D’Alessandro, A.M.; Kalayoglu, M.; Pirsch, J.D. Experience with 500 simultaneous pancreas-kidney transplants. Ann. Surg. 1998, 228, 284-296. [CrossRef] [PubMed]

17. Benedetti, E.; Troppmann, C.; Gillingham, K.; Sutherland, D.E.R.; Payne, W.D.; Dunn, D.L.; Matas, A.J.; Najarian, J.S.; Gruessner, R.W.G. Short- and Long-Term Outcomes of Kidney Transplants with Multiple Renal Arteries. Ann. Surg. 1995, 221, 406-414. [CrossRef]

18. Han, D.; Choi, S.; Kim, S. Microsurgical reconstruction of multiple arteries in renal transplantation. Transplant. Proc. 1998, 30, 3004-3005. [CrossRef]

19. Emiroğlu, R.; Köseoğlu, F.; Karakayalı, H.; Bilgin, N.; Haberal, M. Multiple-artery anastomosis in kidney transplantation. Transplant. Proc. 2000, 32, 617-619. [CrossRef]

20. Aydin, C.; Berber, I.; Altaca, G.; Yigit, B.; Titiz, I. The outcome of kidney transplants with multiple renal arteries. BMC Surg. 2004, 4, 4. [CrossRef]

21. Başaran, Ö.; Moray, G.; Emiroğlu, R.; Alevli, F.; Haberal, M. Graft and patient outcomes among recipients of renal grafts with multiple arteries. Transplant. Proc. 2004, 36, 102-104. [CrossRef]

22. Mazzucchi, E.; Souza, A.A.; Nahas, W.C.; Antonopoulos, I.M.; Piovesan, A.C.; Arap, S. Surgical complications after renal transplantation in grafts with multiple arteries. Int. Braz. J. Urol. 2005, 31, 125-130. [CrossRef]

23. Gawish, A.; Donia, F.; Samhan, M.; Halim, M.; Al-Mousawi, M. Outcome of renal allografts with multiple arteries. Transplant Proc. 2007, 39, 1116-1117. [CrossRef]

24. Hwang, J.; Kim, S.; Park, S.; Choi, B.; Kim, J.; Yang, C.; Kim, Y.; Moon, I. The Long-Term Outcomes of Transplantation of Kidneys With Multiple Renal Arteries. Transplant. Proc. 2010, 42, 4053-4057. [CrossRef]

25. Vázquez, R.; Garcia, L.; Morales-Buenrostro, L.; Gabilondo, B.; Alberú, J.; Vilatobá, M. Renal Grafts with Multiple Arteries: A Relative Contraindication for a Renal Transplant? Transplant. Proc. 2010, 42, 2369-2371. [CrossRef]

26. Laouad, I.; Bretagnol, A.; Fabre, E.; Halimi, J.-M.; Al-Najjar, A.; Boutin, J.-M.; Bruyère, F.; Nivet, H.; Lebranchu, Y.; Büchler, M. Kidney Transplant with Multiple Renal Artery Grafts from Deceased Donors: Are Long-Term Graft and Patient Survival Compromised? Prog. Transplant. 2012, 22, 102-109. [CrossRef] [PubMed]

27. Sezer, T.; Solak, I.; Töz, H.; Kardaslar, B.; Er, A.; Hoscoskun, C. Long-Term Outcomes of Kidney Transplants with Multiple Renal Arteries: A Retrospective Study. Transplant. Proc. 2012, 44, 1697-1699. [CrossRef] [PubMed]

28. Bozkurt, B.; Koçak, H.; Dumlu, E.; Mesci, A.; Bahadir, V.; Tokaç, M.; Hamidioğlu, N.; Ertug, Z.; Süleymanlar, G.; Dinckan, A. Favorable Outcome of Renal Grafts with Multiple Arteries: A Series of 198 Patients. Transplant. Proc. 2013, 45, 901-903. [CrossRef] [PubMed]

29. Sevmis, M.; Demir, M.E.; Merhametsiz, O.; Aktas, S.; Sevmis, S.; Uyar, M. Grafts With Multiple Renal Arteries in Kidney Transplantation. Transplant. Proc. 2021, 53, 933-940. [CrossRef] [PubMed]

30. Daowd, R.; Al Ahmad, A. Renal artery anastomosis to internal or external iliac artery in kidney transplant patients. Saudi J. Kidney Dis. Transplant. 2015, 26, 1009-1012. [CrossRef] [PubMed] 
31. Yarlagadda, S.G.; Coca, S.G.; Formica, R.N.; Poggio, E.D.; Parikh, C.R. Association between delayed graft function and allograft and patient survival: A systematic review and meta-analysis. Nephrol. Dial. Transplant. 2008, 24, 1039-1047. [CrossRef] [PubMed]

32. Nemati, E.; Einollahi, B.; Pezeshki, M.L.; Porfarziani, V.; Fattahi, M.R. Does Kidney Transplantation with Deceased or Living Donor Affect Graft Survival? Nephro-Urol. Mon. 2014, 6, e12182. [CrossRef] 